\title{
Uptake of intermittent preventive treatment for malaria during pregnancy with Sulphadoxine-Pyrimethamine (IPTp-SP) among postpartum women in Zomba District, Malawi: a cross-sectional study
}

\author{
Steven Chifundo Azizi ${ }^{1,2^{*}}$, Gershom Chongwe ${ }^{1}$, Helen Chipukuma ${ }^{3}$, Choolwe Jacobs ${ }^{1}$, Jessy Zgambo ${ }^{1}$
} and Charles Michelo ${ }^{1}$

\begin{abstract}
Background: Malaria in pregnancy causes adverse birth outcomes. Intermittent preventive treatment of malaria during pregnancy with sulphadoxine-pyrimethamine (IPTp-SP) is recommended as a chemoprevention therapy. Zomba district IPTp uptake falls far below the national average. The study was conducted to assess determinants of IPTp-SP uptake during pregnancy among postpartum women in Zomba district after adoption of new IPTp-SP policy in 2014.

Methods: This was a cross-sectional survey. Two public health facilities (HFs) were randomly selected from urban and rural areas in Zomba district. Study participants were postpartum women selected by using exit poll method from HFs. A total of 463 postpartum women were interviewed using structured questionnaire. Bivariate and multiple logistic regression was used in data analysis.

Results: Out of all the enrolled participants $(n=463), 92 \%$ women had complete information for analysis. Of these, ( $n=426)$ women, 127 (29.8\%, 95\% Cl: 25.6\%-34.3\%) received three or more doses of SP, 299 (70.2\%, 95\% Cl: 65.7\%$74.4 \%)$ received two or less doses. Women receiving SP from rural HF were less likely to get at least three doses of $\mathrm{SP}$ than urban women, $(\mathrm{AOR}=0.31,95 \% \mathrm{Cl} 0.13-0.70)$; Others less likely were those with three or few antenatal care (ANC) visits versus four or more visits ( $\mathrm{AOR}=0.29,95 \% \mathrm{Cl} 0.18-0.48)$; not taking SP under direct observation therapy (DOT) $(\mathrm{AOR}=0.18,95 \% \mathrm{Cl}(0.05-0.63)$.
\end{abstract}

Conclusions: There is low utilisation of at least three doses of SP in this population and this seems to be associated with the number of ANC visits and use of DOTs. These determinants may therefore be important in shaping interventions aimed at increasing the uptake of IPTp in this district. In addition, the rural urban differential suggests the need for further research to understand the barriers and enablers of uptake in each context in order to improve the health of the community.

Keywords: Pregnancy, Intermittent preventive treatment, Sulphadoxine-pyrimethamine, Malaria, Uptake, Postpartum, Malawi

\footnotetext{
*Correspondence: steve_aziz@hotmail.com

1Department of Epidemiology and Biostatistics, School of Public Health,

University of Zambia, Post Box 50110, Lusaka, Zambia

${ }^{2}$ Malawi Defence Force, Malawi Military Health Services, Kamuzu Barracks,

Private Bag 43, Lilongwe, Malawi

Full list of author information is available at the end of the article
}

(c) The Author(s). 2018 Open Access This article is distributed under the terms of the Creative Commons Attribution 4.0 International License (http://creativecommons.org/licenses/by/4.0/), which permits unrestricted use, distribution, and reproduction in any medium, provided you give appropriate credit to the original author(s) and the source, provide a link to the Creative Commons license, and indicate if changes were made. The Creative Commons Public Domain Dedication waiver (http://creativecommons.org/publicdomain/zero/1.0/) applies to the data made available in this article, unless otherwise stated. 


\section{Background}

Malaria in pregnancy (MiP) is a significant cause of maternal morbidity and poor birth outcomes yet is preventable and treatable [1-4]. Women are particularly predisposed to adverse effects of malaria during their first and second pregnancies [5]. Globally, it is estimated that 125 million pregnant women are at risk of malaria infection each year and 30 million come from sub-Saharan Africa [6]. Furthermore, 75,000-200,000 infants and 10, 000 women deaths are estimated annually and the deaths are attributed to MiP [6, 7]. Particularly, Plasmodium falciparum infections in pregnancy contributes to approximately $11 \%$ $(100,000)$ of neonatal deaths due to low birth weight in areas of Africa where malaria is endemic (LBW) [7-9]. Infection with malaria in pregnancy predisposes women to increased risk of severe anaemia, intra-uterine growth retardation, intrauterine death, stillbirth, pre-term delivery, low birth weight (LBW), maternal death and placental malaria; and there is increased risk to unborn baby from miscarriage, stillbirth and LBW [10-12].

World Health Organisation (WHO) recommends threepronged approach in stable malaria transmission areas for malaria prevention and control in pregnancy, which are Intermittent Preventive Treatment of malaria during pregnancy with sulphadoxine-pyrimethamine (IPTp-SP) , use of insecticides treated nets (ITNs), and prompt diagnosis and effective treatment. In the IPTp-SP interventional regimen, each dose contains three tablets of sulphadoxine/pyrimethamine and each tablet contains $500 \mathrm{mg} / 25 \mathrm{mg}$ SP $[13,14]$. Although in 2004, WHO recommended a minimum of two doses of IPTp-SP during pregnancy $[15,16]$, in October 2012 this policy was updated to "at least three doses during pregnancy and to be administered at least 1 month apart at each scheduled antenatal care (ANC) visit, beginning from second trimester under direct observational therapy" $[17,18]$. Malawi adopted the updated policy in 2013 [19]. WHO envisage the policy would increase IPTp-SP uptake as it also recommends at least four ANC visits during the second and third trimesters of pregnancy under the Focused antenatal care (FANC) model [17, 20]. Roll Back Malaria set a target of $100 \%$ utilization of at least two doses of IPTp-SP by 2015 [21]. Antenatal Care is the main point of contact of pregnant women with the health system [7]. ANC clinics are used as a vehicle of coverage of health interventions against malaria and other adverse conditions. Thus, the uptake of IPTp-SP would depend on attendance of pregnant women and delivery of the intervention at a health facility $[16,22]$.

Studies that estimated proportions of uptake of at least three doses of IPTp-SP and identified factors associated with it among pregnant women are few since WHO updated the IPTp-SP policy. However, previous studies revealed that, successful uptake of at least two doses of IPTp-SP is determined by the number of ANC visits [4, 18, 23-28], directly observed therapy (DOT) $[4,29,30]$, residential area $[18,31]$, age of woman [31], education level and socioeconomic status [4,32], parity $[4,31]$, timing of initial ANC visit [4, 33], knowledge about malaria/IPTp [4] and stockouts of the commodity [4]. This study envisages to contribute to identifying obstacles to completion of recommended doses of SP during pregnancy using the updated policy in order to develop a robust and multidisciplinary implementation approach for IPTp-SP intervention in resource limited settings. The aims of the study were to estimate the proportion of and identify factors determining the uptake of at least three doses of IPTp-SP among pregnant women in Zomba district, Malawi.

\section{Methods}

\section{Study design and study settings}

A cross sectional study was conducted in two health facilities in Zomba district, which is located in the southern region of Malawi between November 23, 2016 and January 27, 2017. Zomba district was purposively chosen because it was among the districts that had the lowest IPTp uptake in Malawi [34].

\section{Study population}

The target population was all pregnant women and the study population was all postpartum women aged 15-49 who had just delivered $(<48 \mathrm{~h})$ and those that delivered at home but visited the health facility for check-up at a randomly sampled Government-owned health facility in Zomba district.

\section{Inclusion and exclusion criteria}

The study included postpartum women of the ages between 15 to 49 years who delivered at Government Health facility (HF), or delivered at home but brought a baby to HF within $48 \mathrm{~h}$ for check-up to minimise recall bias. They had singleton pregnancy, absence of reported antimalarial treatment other than SP in the previous 1 month. On the other hand, complicated cases of pregnancy, postpartum women on cotrimoxazole prophylaxis during their pregnancy because of increased risk of adverse drug reactions when taken together with SP were excluded from the study [14, 35].

\section{Variables}

Guided by literature review, the study included the following variables that had been theoretically and empirically linked to malaria in pregnancy and uptake of IPTp-SP. The outcome was IPTp-SP uptake ( $\leq 2$ doses versus $3+$ doses) and. Explanatory variables were age, marital status, residence (location of the health facility), level of education, occupation, religion, tribe, knowledge about malaria 
transmission, knowledge about dangers of malaria in pregnancy, parity, number and timing of antenatal clinic visits, taking SP each time under directly observed therapy, distance to health facility, need for spouse's escort to ANC, worried no health care provider and drugs at health facility and gravida (Table 1).

\section{Sampling and sample size determination}

The district was divided into two sites according to residential settings: rural and urban. All Government owned health facilities that offered maternity and antenatal services were included in the stratified sampling frame. There were seven public health facilities out of 15 that were offering maternity and antenatal services in rural. Only two public health facilities among five offered maternity and antenatal services in urban. One health facility was selected from each stratum using simple random sampling drawn from Excel spreadsheet "RAND()" command.
Sample size was determined using a single population proportion estimation formula and calculated using Epi Info 7 with $43.5 \%$ proportion [34], $5 \%$ of decision precision, $95 \%$ confidence interval and non-response rate of $20 \%$. The calculated overall sample size was 454 .

Since the number of deliveries varies for different health facilities, a proportionate method was used for determining the sample size for each facility. The sample for each facility was calculated by weighting the total sample size required with the relative proportion of clients (total deliveries for each facility, as reported by the heads of the facilities) for the week prior to beginning of data collection as numerator; and the sum of deliveries in all the facilities as denominator [36]. Systematic sampling was employed to choose postpartum women as they existed from the labour ward at a specified interval by using the estimate of the average clinic deliveries to calculate sampling interval. The first participant was

Table 1 Variables used in the study

\begin{tabular}{|c|c|c|}
\hline Variable & Definition & Measurement scale \\
\hline IPTp-SP uptake (Primary outcome) & Two or less $(\leq 2)$ doses is incomplete and three or more $(3+)$ is optimal & Nominal/binary \\
\hline \multicolumn{3}{|l|}{ Explanatory variable } \\
\hline Age group & Age of a woman & Nominal \\
\hline Marital status & Marital status of a woman & Nominal \\
\hline Residence (Zone) & Type of woman's residence & Nominal/binary \\
\hline Education & Level of education of woman & Nominal \\
\hline Occupation & Woman's occupation & Nominal \\
\hline Religion & Woman's religion & Nominal \\
\hline Tribe & Woman's tribe & Nominal \\
\hline First pregnancy & Woman's first pregnancy & Nominal/binary \\
\hline Parity & Number of birth that a woman had after 20 weeks gestation & Nominal \\
\hline Timing of 1st ANC visit & $\begin{array}{l}\text { Age of the pregnancy a first time a woman visited antenatal } \\
\text { care clinic (ANC) }\end{array}$ & Nominal \\
\hline ANC visits & $\begin{array}{l}\text { Number of antenatal care visits a pregnant woman made during } \\
\text { her gestation period }\end{array}$ & Nominal \\
\hline Gravida & $\begin{array}{l}\text { Total number of confirmed pregnancies that a woman had } \\
\text { regardless of the outcome }\end{array}$ & Nominal \\
\hline Knowledge of malaria transmission & $\begin{array}{l}\text { Three items (sugarcane, mosquito, witchcraft). If only mosquito is selected } \\
\text { as the an agent of transmission, then the person is knowledgeable, otherwise } \\
\text { inadequate knowledge }\end{array}$ & Nominal/binary \\
\hline Knowledge of dangers of malaria in pregnancy & $\begin{array}{l}\text { Three items (abortion, still birth, low birth weight) indicated knowledgeable } \\
\text { of consequences of malaria in pregnancy. Otherwise, inadequate knowledge }\end{array}$ & Nominal/binary \\
\hline Took SP under DOT each time & $\begin{array}{l}\text { Whether a woman took SP under direct observation therapy (DOT) strategy } \\
\text { or not }\end{array}$ & Nominal/binary \\
\hline Permission to go to HF & Seeking permission from spouse to visit health facility (HF) for ANC & Nominal/binary \\
\hline Distance to HF & Distance to health facility from a woman's residence & Nominal/binary \\
\hline Transport to HF & Transportation to heath facility & Nominal/binary \\
\hline Need for spouse escort to HF & Spouse escort to health facility & Nominal/binary \\
\hline Worried no health provider at HF & Worried that there would be no health care provider & Nominal/binary \\
\hline Worried no drugs at HF & Worried that there might be no drugs at clinic & Nominal/binary \\
\hline
\end{tabular}


enrolled at random. The random selection was done by entering all the names of women discharged at a particular day in Excel spreadsheet and executed RAND() command.

\section{Data collection and quality management}

A total of six public nurses were recruited and trained in data collection methods and management for 2 days, followed by one-day fieldwork. This was done to ensure the data collected were consistent across data collectors, complete and valid. The investigator monitored and supervised the data collectors throughout the data collection exercise.

The study used a structured interviewer-administered questionnaire with some questions adapted from 2014 Malawi Malaria Indicator Survey and 2010 Malawi Demographic and Health Survey [34, 37] (Additional file 1). The questionnaire solicited data on demographic, number of IPTp-SP doses a woman received during pregnancy, knowledge about malaria and IPTp-SP, number of and timing of antenatal clinic visits, parity and gravida. Number of ANC visits, number of IPTp-SP doses received, date of the first ANC visit, and woman's age were the data that were obtained from the questionnaire and triangulated by women's ANC cards and health facility records. The cards and records were used to verify verbal reports and whenever there was information discordance, the cards and records data were collected.

The questionnaire was administered by trained nurses (interviewers). The English version questionnaire was translated into Chichewa, which is a local language by a multilingual person. Another individual with knowledge of both English and Chichewa translated the Chichewa version back to English to check consistency in meaning. The questionnaire was pre-tested on 30 postpartum women from peri-urban health facility. Results from the pre-test exercise were discussed among the research team and a revised version of the questionnaire was adopted to be used in data collection. During data collection process, the investigator checked $15 \%$ of the completed questionnaires for completeness and consistency and where necessary provided feedbacks to data collectors.

A template of the questionnaire was prepared using EpiData 3.1 (CDC, Atlanta, GA, USA) and data were entered into the software and validated by a second data entry (double entry). The data were then exported into Stata version 14.2 (Stata Corp, College Station, Tx, USA) for further cleaning and analysis.

\section{Data analysis}

Data were summarised in the form of proportions and frequencies for categorical variables. Means with their respective standard deviations were used to summarise the data if the variables were continuous and normally distributed, otherwise median and respective interquartile range were used.

Bivariate binary logistic regression analysis was performed to determine the presence or absence of association between outcome and respective explanatory variables by generating crude odds ratios (OR). All explanatory variables with $p<0.20$ in the bivariate analysis were included in both automated and investigator-led backward-stepwise multiple binary logistic regression analysis to further examine the association between the outcome and each explanatory variable while controlling the effects of other explanatory variables by calculating adjusted odds ratios (AOR) The level of significance used was 5\% (0.05), two-tailed at 95\% confidence interval $(\mathrm{CI})$. The $\mathrm{CI}$ for proportions were calculated using logit transformation, which is a default option in Stata.

\section{Assessment of goodness of fit of the models}

The goodness of fit of the models was tested using likelihood ratio (LR), and Homsmer and Lemeshow tests. The full model consisting of all the independent variables was compared with the model created by backward stepwise regression at 5\% significant level. Test result with significant level above $5 \%$ was interpreted as a model with fewer independent variables and better than the full model. The classification ability of the models was evaluated using Receiver Operating Characteristics (ROC) curve. The ROC value above 0.5 meant that a model classification was not due to chance.

The Likelihood ratio (LR) chi-square with $22^{\circ}$ degrees of freedom was $14.09, p$-value $=0.898$. This means the model with fewer (nine) explanatory variables was better model than the one with 21 variables. The HosmerLemeshow goodness-of-fit test was found to be not significant $\left(x^{2}=8.39, d f=8, p=0.396\right)$. Thus we do not have enough evidence to reject the null hypothesis that the model fitted the data well. Furthermore, ROC value for the selected model as shown in Fig. 1 is 0.77, which suggests that classification is not due to chance as ROC value is close to 1 than 0.5 .

\section{Ethical approval and consent to participate}

Ethics approval was obtained from National Health Sciences Research Committee in Malawi (issued September 12, 2016, protocol number 1656) and University of Zambia Biomedical Research Ethics Committee in Zambia (issued August 3, 2016, reference number 017-06-16). Written permission to conduct the study in the health facilities (Matawale and Likangala) was obtained from Zomba District Health Office health facilities involved in the study. Informed written consents and assents were obtained from study participants whose age was 18 years and above and below 18 years respectively. Willingness to participate in the study and parental permission was 


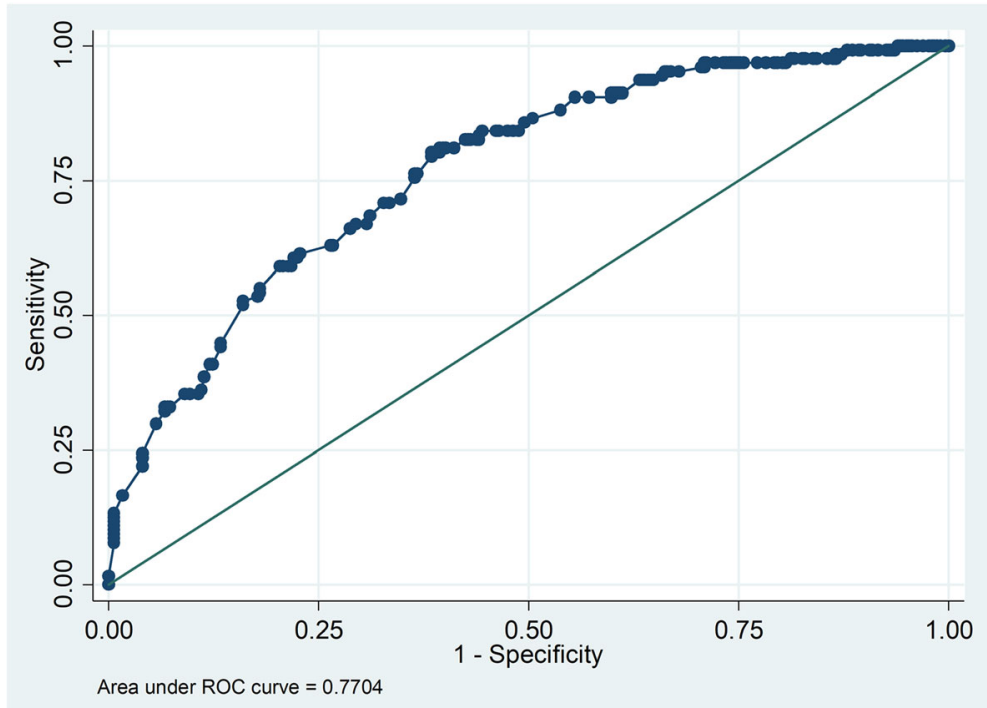

Fig. 1 Receiver Operating Characteristic (ROC) curve

confirmed by signing (finger print for illiterates) on the informed consent sheet.

\section{Results}

\section{Prevalence of IPTP-SP uptake}

A total of 463 women were enrolled into the study. Out of this, 426 (92\%) women with complete information had their data analysed to investigate the determinants of IPTp-SP uptake. Of 426 women, 127 (29.8\%, 95\% CI: $25.6 \%-34.3 \%$ ) received three (optimal) or more doses of SP, 299 (70.2\%, 95\% CI: 65.7\%-74.4\%) received two or less doses (poor uptake or suboptimal).

\section{Sociodemographic characteristics of participants}

Out of 426 women, $55 \%$ delivered at urban health facility and $45 \%$ delivered at the rural health facility. Of 233 women who delivered at urban health facility, $40 \%$ took three or more doses and 60\% received two or less doses of SP during pregnancy. Among 193 delivering women at rural health centre, $17 \%$ received three or more doses while $83 \%$ took two or less doses of SP. More than half (232, 54\%) of participants had completed at least senior primary school. Pregnant women in the age group 2535 had the highest uptake of optimal SP doses compared to the rest of the women. Women who were divorced or separated or widowed had highest percentage of taking optimal SP doses (Table 2).

\section{Cultural characteristics}

Women who had problems with spouses' escort to ANC clinic had higher percentage (42\%) of receiving three or more doses than those who had no problem with escorts (23\%). Participants with a small problem in getting permission from their spouse to visit HF had a slight higher percentage (30\%) of completing SP doses than women who had a big problem with seeking permission (25\%). Women who first visited ANC in first trimester had the highest percentage of completing the recommended doses (Table 3).

\section{Individual characteristics}

The percentages for completing SP doses were similar for both primigravida and multigravida $(29.9 \%$ vs $29.5 \%$ respectively). At least four ANC visits a pregnant woman made was associated with higher proportion of taking three or more SP doses than three or less visits. Both groups of women who were knowledgeable and partially knowledgeable about malaria transmission had similar percentages of taking three or more doses of SP $(29.8 \%$ vs $30 \%)$. However, those women who were aware of dangers of malaria in pregnancy had higher percentage (32\%) of completing recommended SP doses than those with inadequate knowledge (25\%) (Table 4).

\section{Structural factors (access to health facility and provider readiness) faced by participant}

Pregnant women who took SP under Direct Observation Therapy (DOT) each time had higher percentage of completing three or more doses than those who did not take SP under DOT each time they visited ANC (33\% vs 6\%). Participants who had problems with long distance and lack of transport to health facility had lower percentage of completing the recommended doses. The women who worried most that there would be no health provider at HF had lower percentage $(20 \%)$ of completing the recommended 
Table 2 Sociodemographic characteristics of participants by IPTp uptake

\begin{tabular}{|c|c|c|c|c|c|}
\hline \multirow[t]{3}{*}{ Characteristic } & \multirow{3}{*}{$\begin{array}{l}N \\
(\text { Total }=426)\end{array}$} & \multicolumn{4}{|c|}{$\%$ of women who took IPTp } \\
\hline & & $\leq 2$ doses $^{a}$ & $95 \% \mathrm{Cl}$ & $3+$ doses $^{b}$ & $95 \% \mathrm{Cl}$ \\
\hline & & \multicolumn{2}{|l|}{ n (\%) } & \multicolumn{2}{|l|}{ n (\%) } \\
\hline \multicolumn{6}{|l|}{ Zone } \\
\hline Urban & 233 & $139(59.7)$ & $53.2-65.8$ & $94(40.3)$ & $34.2-46.8$ \\
\hline Rural & 193 & $160(82.9)$ & $76.9-87.6$ & $33(17.1)$ & $12.4-23.1$ \\
\hline \multicolumn{6}{|l|}{ Education } \\
\hline No formal education/junior primary & 194 & $130(67.0)$ & $60.0-73.3$ & $64(33.0)$ & $26.7-39.9$ \\
\hline Senior primary & 125 & $97(77.6)$ & $69.4-84.1$ & $28(22.4)$ & $15.9-30$. \\
\hline Secondary/tertiary & 107 & $72(67.3)$ & $57.8-75.6$ & $35(32.7)$ & $24.4-42.2$ \\
\hline \multicolumn{6}{|l|}{ Age group } \\
\hline $15-24$ & 201 & $146(72.6)$ & $66.0-78.4$ & $55(27.4)$ & $21.6-33.9$ \\
\hline $25-34$ & 176 & $114(64.8)$ & $57.4-71.5$ & $62(35.2)$ & $28.5-42.6$ \\
\hline $35+$ & 49 & $39(79.6)$ & $65.9-88.7$ & $10(20.4)$ & $11.3-34.1$ \\
\hline \multicolumn{6}{|l|}{ Occupation } \\
\hline Unemployed & 307 & $228(74.3)$ & $69.1-78.9$ & $79(25.7)$ & $21.1-30.9$ \\
\hline Self-employed & 104 & $64(61.5)$ & $51.8-70.4$ & $40(38.5)$ & $29.6-48.2$ \\
\hline Employed & 15 & $7(46.7)$ & $23.4-71.5$ & $8(53.3)$ & $28.5-76.6$ \\
\hline \multicolumn{6}{|l|}{ Marital status } \\
\hline Married & 382 & $272(71.2)$ & $66.4-75.5$ & $110(28.8)$ & $24.5-33.6$ \\
\hline Divorced/separated/widowed & 19 & $10(52.6)$ & $30.5-73.8$ & $9(47.4)$ & $26.2-69.5$ \\
\hline Never married & 25 & $17(68.0)$ & $47.3-83.4$ & $8(32.0)$ & $16.6-52.7$ \\
\hline \multicolumn{6}{|l|}{ Religion } \\
\hline $\mathrm{CCAP}^{c} / 7$ th day $^{d} /$ Baptist & 112 & $70(62.5)$ & $53.1-71.0$ & $42(37.5)$ & $28.9-46.9$ \\
\hline Other Christian & 134 & $102(76.1)$ & $68.1-82.6$ & $32(23.9)$ & $17.4-31.9$ \\
\hline Catholic/Anglican & 93 & $65(69.9)$ & $59.8-78.4$ & $28(30.1)$ & $21.6-40.2$ \\
\hline Muslim/other religions & 87 & $62(71.3)$ & $60.8-79.8$ & $25(28.7)$ & $20.2-39.2$ \\
\hline \multicolumn{6}{|l|}{ Tribe } \\
\hline Nyanja & 106 & $85(80.2)$ & $71.4-86.8$ & $21(19.8)$ & $13.2-28.6$ \\
\hline Chewa & 107 & $69(64.5)$ & $54.9-73.0$ & $38(35.5)$ & $26.9-45.1$ \\
\hline Lomwe & 102 & 75 (73.5) & $64.1-81.2$ & $27(26.5)$ & $18.8-35.9$ \\
\hline Other & 111 & $70(63.1)$ & $53.7-71.6$ & $41(36.9)$ & $28.4-46.3$ \\
\hline
\end{tabular}

${ }_{\text {uptake of two or less doses of IPTp-SP }}$

$b$ uptake of three or more doses of IPTp-SP

'Church of Central Africa Presbyterian

${ }^{d}$ Seventh Day Adventist

doses against $35 \%$ for participants who felt otherwise (Table 5).

\section{Determinants of uptake of IPTp-SP Bivariate analysis}

Bivariate logistic regression results showed that 12 out of 21 predictor variables were significantly associated with completion of the recommended doses of SP during pregnancy (Table 6). Significant barriers to completion of recommended SP doses by a pregnant women: Attending ANC from health facility in rural setting compared to urban setting $(\mathrm{OR}=0.30,95 \% \mathrm{CI}$ : 0.19-0.48, $p<0.001)$, women who attained senior primary school education than women without formal or junior primary education $(\mathrm{OR}=0.58,95 \% \mathrm{CI}$ : $0.35-0.98, p=0.043)$, being a member of other Christian denomination than a member of Church of Central Africa Presbyterian (CCAP) or Seventh Day Adventist or Baptist (OR =0.52, 95\% CI: 0 . $30-0.91, p=0.021$ ), commencing ANC in third trimester than in second trimester $(\mathrm{OR}=0.26,95 \% \mathrm{CI}$ : 0.09-0.67, $p=0.005)$, three or less number of ANC visits against four or more visits $(\mathrm{OR}=0.31,95 \% \mathrm{CI}: 0.19-0.49, p<0$. 001), not taking SP doses under direct observation of health care provider $(\mathrm{OR}=0.13,95 \% \mathrm{CI}$ : $0.04-0.43, p=0.001$ ), 
Table 3 Cultural characteristics by IPTp uptake

\begin{tabular}{|c|c|c|c|c|c|}
\hline \multirow[t]{2}{*}{ Characteristic } & \multirow{2}{*}{$\begin{array}{l}N \\
(\text { Total }=426)\end{array}$} & \multicolumn{4}{|c|}{ \% of women who took IPTp } \\
\hline & & $\leq 2$ doses & $95 \% \mathrm{Cl}$ & $3+$ doses & $95 \% \mathrm{Cl}$ \\
\hline \multicolumn{6}{|c|}{ Permission to go to $\mathrm{HF}^{a}$} \\
\hline $\begin{array}{l}\text { Small } \\
\text { problem }\end{array}$ & 410 & $287(70.0)$ & $65.3-74.3$ & $123(30.0)$ & $25.7-34.6$ \\
\hline $\begin{array}{l}\text { Big } \\
\text { problem }\end{array}$ & 16 & $12(75.0)$ & $48.2-90.6$ & $4(25.0)$ & $9.4-51.8$ \\
\hline \multicolumn{6}{|c|}{ Need for spouse escort to HF } \\
\hline $\begin{array}{l}\text { Small } \\
\text { problem }\end{array}$ & 276 & $212(76.8)$ & 71.4-81.4 & $64(23.2)$ & $18.6-28.6$ \\
\hline $\begin{array}{l}\text { Big } \\
\text { problem }\end{array}$ & 150 & $87(58)$ & $49.9-65.7$ & $63(42.0)$ & $34.3-50.1$ \\
\hline \multicolumn{6}{|c|}{ Timing of 1st ANC visit } \\
\hline $\begin{array}{l}\text { 2nd } \\
\text { trimester }\end{array}$ & 284 & $198(69.7)$ & $64.1-74.8$ & $86(30.3)$ & $25.2-35.9$ \\
\hline $\begin{array}{l}1 \mathrm{st} \\
\text { trimester }\end{array}$ & 92 & $56(60.9)$ & $50.5-70.4$ & $36(39.1)$ & $29.6-49.5$ \\
\hline $\begin{array}{l}\text { 3rd } \\
\text { trimester }\end{array}$ & 50 & $45(90.0)$ & 77.9-95.8 & $5(10.0)$ & $4.2-22.1$ \\
\hline
\end{tabular}

${ }^{a}$ Heath Facility distance to health facility $(\mathrm{OR}=0.37,95 \% \mathrm{CI}: 0.19-0.71$, $p=0.003)$, transport problem to health facility ( $\mathrm{OR}=0$. 42 , 95\% CI: $0.23-0.78, p=0.006)$, and worried that there would be no drugs at health facility $(\mathrm{OR}=0.54$, 95\% CI: 0.34-0.84, $p=0.006$ ).

The enabling determinants significantly associated with a pregnant woman to more likely to complete recommended doses were: being self-employed woman versus unemployed women $(\mathrm{OR}=1.80,95 \% \mathrm{CI}: 1.13-2.89$, $p=0.014)$, being employed against unemployed ( $\mathrm{OR}=$ 3.30, 95\% CI: $1.15-9.39, p=0.025)$, being Chewa tribe than Nyanja tribe (OR $=2.23,95 \% \mathrm{CI}: 1.19-4.15, p=0.011)$, being of other tribe rather than Nyanja $(\mathrm{OR}=2.37,95 \% \mathrm{CI}$ : $1.28-4.38, p=0.006$ ), and having problems with spouse escort to health facility $(\mathrm{OR}=2.40,95 \% \mathrm{CI}: 1.56-3.68$, $p<0.001)$.

\section{Multivariable analysis}

In multiple binary logistic regression results, six out of nine explanatory variables were significantly associated with a pregnant woman receiving at least three doses of SP. Only two enablers were significantly associated with a pregnant woman completing at least recommended SP

Table 4 Clinical characteristics and level of knowledge among participants by IPTp uptake

\begin{tabular}{|c|c|c|c|c|c|}
\hline \multirow[t]{3}{*}{ Characteristic } & \multirow{3}{*}{$\begin{array}{l}\mathrm{N} \\
(\text { Total }=426)\end{array}$} & \multicolumn{4}{|c|}{$\%$ of women who took IPTp } \\
\hline & & $\leq 2$ doses & $95 \% \mathrm{Cl}$ & $3+$ doses & $95 \% \mathrm{Cl}$ \\
\hline & & \multicolumn{2}{|l|}{ n (\%) } & \multicolumn{2}{|l|}{ n (\%) } \\
\hline \multicolumn{6}{|l|}{ First pregnancy } \\
\hline No & 304 & $213(70.1)$ & $64.7-75.0$ & $91(29.9)$ & $25.0-35.3$ \\
\hline Yes & 122 & $86(70.5)$ & $61.8-77.9$ & $36(29.5)$ & $22.1-38.2$ \\
\hline \multicolumn{6}{|l|}{ Parity } \\
\hline One child & 121 & $85(70.3)$ & $61.5-77.8$ & $36(29.8)$ & $22.2-38.5$ \\
\hline Two children & 111 & $72(64.9)$ & $55.5-73.2$ & $39(35.1)$ & $26.8-44.5$ \\
\hline $3+$ children & 194 & $142(73.2)$ & $66.5-78.9$ & $52(26.8)$ & $21.0-33.5$ \\
\hline \multicolumn{6}{|l|}{ ANC visits } \\
\hline $4+$ & 234 & $140(59.8)$ & $53.3-65.9$ & $94(40.2)$ & $34.1-46.6$ \\
\hline Three or less & 192 & $159(82.8)$ & $76.8-87.5$ & $33(17.2)$ & $12.5-23.2$ \\
\hline \multicolumn{6}{|l|}{ Gravida } \\
\hline multigravida $^{a}$ & 194 & $141(72.7)$ & $65.9-78.5$ & $53(27.3)$ & $21.5-34.1$ \\
\hline Secundigravida ${ }^{\mathrm{b}}$ & 110 & $72(65.4)$ & $56.0-73.8$ & $38(34.6)$ & $26.2-43.9$ \\
\hline primigravida $^{c}$ & 122 & $86(70.5)$ & $61.8-77.9$ & $36(29.5)$ & $22.1-38.2$ \\
\hline \multicolumn{6}{|c|}{ Knowledge of malaria transmission } \\
\hline knowledgeable & 386 & $271(70.2)$ & $65.4-74.6$ & $115(29.8)$ & $25.4-34.6$ \\
\hline Inadequate Knowledge & 40 & $28(70.0)$ & $54.0-82.3$ & $12(30.0)$ & $17.7-46.0$ \\
\hline \multicolumn{6}{|c|}{ Knowledge of dangers of malaria in pregnancy } \\
\hline Knowledgeable & 303 & $207(68.3)$ & $62.8-73.3$ & $96(31.7)$ & $26.7-37.2$ \\
\hline Inadequate knowledge & 123 & $92(74.8)$ & $66.3-81.7$ & $31(25.2)$ & $18.3-33.7$ \\
\hline
\end{tabular}

a woman that has been pregnant for at least a second time

b a woman in her second pregnancy

ca woman who is pregnant for the first time 
Table 5 IPTp uptake against factors that affect access to health facility and health provider DOT adherence

\begin{tabular}{|c|c|c|c|c|c|}
\hline \multirow[t]{2}{*}{ Characteristic } & \multirow{2}{*}{$\begin{array}{l}N \\
(\text { Total }=426)\end{array}$} & \multicolumn{4}{|c|}{$\%$ of women who took IPTp } \\
\hline & & $\leq 2$ doses & $95 \% \mathrm{Cl}$ & $3+$ doses & $95 \% \mathrm{Cl}$ \\
\hline \multicolumn{6}{|c|}{ Took SP under DOT ${ }^{\mathrm{a}}$ each time } \\
\hline Yes & 376 & $252(67.0)$ & $62.1-71.6$ & $124(32.9)$ & $28.4-37.9$ \\
\hline No & 50 & $47(94.0)$ & $82.8-98.1$ & $3(6.0)$ & $1.9-17.2$ \\
\hline \multicolumn{6}{|l|}{ Distance to HF } \\
\hline $\begin{array}{l}\text { Small } \\
\text { problem }\end{array}$ & 348 & $233(67.0)$ & $61.8-71.7$ & $115(33.1)$ & $28.3-38.2$ \\
\hline $\begin{array}{l}\text { Big } \\
\text { problem }\end{array}$ & 78 & $66(84.6)$ & $74.7-91.1$ & $12(15.4)$ & $8.9-25.3$ \\
\hline \multicolumn{6}{|c|}{ Transport to HF } \\
\hline $\begin{array}{l}\text { Small } \\
\text { problem }\end{array}$ & 344 & $231(67.2)$ & $61.9-71.9$ & $113(32.9)$ & $28.1-38.0$ \\
\hline $\begin{array}{l}\text { Big } \\
\text { problem }\end{array}$ & 82 & $68(82.9)$ & $73.1-89.7$ & $14(17.1)$ & $10.3-26.9$ \\
\hline \multicolumn{6}{|c|}{ Worried no health provider at HF } \\
\hline $\begin{array}{l}\text { Small } \\
\text { problem }\end{array}$ & 280 & $183(65.4)$ & $59.6-70.7$ & $97(34.6)$ & $29.3-40.4$ \\
\hline $\begin{array}{l}\text { Big } \\
\text { problem }\end{array}$ & 146 & $116(79.5)$ & $72.1-85.3$ & $30(20.0)$ & $14.7-27.9$ \\
\hline \multicolumn{6}{|c|}{ Worried no drugs at HF } \\
\hline $\begin{array}{l}\text { Small } \\
\text { problem }\end{array}$ & 263 & $172(65.4)$ & $59.4-70.9$ & $91(34.6)$ & $29.1-40.6$ \\
\hline $\begin{array}{l}\text { Big } \\
\text { problem }\end{array}$ & 163 & $127(77.9)$ & $70.8-83.6$ & $36(22.1)$ & $16.3-29.1$ \\
\hline
\end{tabular}

${ }^{\mathrm{a}}$ Direct Observation Therapy

doses. First, being in the age group 25-34 compared to age group $15-24$ (AOR $=1.72,95 \% \mathrm{CI}: 1.06-2.78, p=0$. 028). Second, pregnant women with problem of spouse escort to health facility (AOR $=2.03,95 \%$ CI: $1.26-3.26$, $p=0.004)$.

The following determinants made a pregnant woman less likely to complete at least the recommended doses of SP after adjusting for other independent variables. Pregnant women who attended ANC from health facility in rural setting than those from urban settings (AOR = 0.31, 95\% CI: 0.13-0.70, $p=0.005)$, pregnant women who had three or less ANC visits (AOR $=0.29,95 \% \mathrm{CI}$ : $0.18-0.48, p<0.001$ ), women who did not take doses of SP under direct observations of health care provider (AOR $=0.18,95 \%$ CI: 0.05-0.63, $p=0.007$ ), and being a Catholic or Anglican member compared to a member of Church of Central Africa Presbyterian (CCAP) or Seventh Day Adventist (AOR $=0.53,95 \%$ CI: 0.28-0.97, $p=0.041)$. The results are presented in Table 6 .

\section{Discussion}

The WHO new recommended doses of IPTp-SP uptake was very low in the study population when comparing to Roll Back Malaria (RBM) benchmark target for all pregnant women in areas with moderate-to-high transmission in Africa [7]. Some of the factors associated with the low uptake that the study found were attending ANC clinic in rural area, three or less ANC visits, not taking SP under DOT.

Health facility location/women's residential area setting has been found in this study to be related to uptake of IPTp-SP. Women who attended rural health facility were less likely to complete the recommended SP doses during pregnancy. This finding is similar to a study done in Geita district, Tanzania [18] and Nigeria [36]. To the best knowledge of the authors, the Geita-Tanzania study was the only study that evaluated uptake of IPTp-SP, categorised into less than three doses versus three or more doses of SP, at the time of writing this paper. This observation might either indicate that rural health facility had lower stock levels of SP than urban health facility because of poor supply chain from district health office (DHO) due to challenges in transportation of the commodity or understaffing [4] which leads to high clientto-staff ratios and subsequently long queues and waiting times. This could prompt some pregnant women not make further ANC visits. Kibusi et al. [31] reported that being a resident of Eastern Zone (urban) in Tanzania was associated with completing two or more doses of SP. This implies that Zomba District Health Office (ZDHO) should strive to strength the rural health systems and achieve equity. On the other hand, there is need for further investigation into the rural-urban differential to understand the real barriers and enablers of uptake in each context in order to improve the health of the community.

This study has shown that receipt of at least three doses of SP was higher among pregnant women making four or more ANC clinic visits than those making three or less visits. The finding is consistent with a study conducted in Tanzania [18, 24], in Ghana [27], in Burkina Faso [25], and in Mali [26, 28] in Cameroon, and in Benin [23]. ANC clinic is the vehicle that carries the intervention from the healthcare provider to the pregnant woman, hence the more visits a pregnant woman makes to ANC clinics the higher the number of SP doses she would receive as long as the visits are scheduled at least 1 month apart beginning from second trimester. Out of 426 women, 234 (55\%) made at least four ANC visits but only 94 out of 234 (40\%) received optimal doses of SP. This suggests a missed opportunity to provide the recommended doses of SP to women who attended WHO recommended number of at least four scheduled ANC visits, as two-thirds (284 out of 426) of the women commenced ANC clinic in the second trimester. The mismatch between percentage of four or more ANC visits and percentage of receipt of three or more doses could occur in part because of intermittent 
Table 6 Factors associated with uptake of three or more doses of IPTp-SP among postpartum women, N=426

\begin{tabular}{|c|c|c|c|c|c|}
\hline Characteristics & $N$ & Crude Odds Ratio $(95 \% \mathrm{Cl})$ & Unadjusted $p$-value ${ }^{a}$ & Adjusted Odds Ratio (95\%Cl) & Adjusted $p$-value ${ }^{b}$ \\
\hline \multicolumn{6}{|l|}{ Zone } \\
\hline Urban & 233 & 1 & & 1 & \\
\hline Rural & 193 & $0.30(0.19-0.48)$ & $<0.001$ & $0.31(0.13-0.70)$ & 0.005 \\
\hline \multicolumn{6}{|l|}{ Education } \\
\hline No formal education/junior primary & 194 & 1 & & & \\
\hline Senior primary & 125 & $0.58(0.35-0.98)$ & 0.043 & & \\
\hline Secondary/tertiary & 107 & $0.99(0.60-1.63)$ & 0.961 & & \\
\hline \multicolumn{6}{|l|}{ Age group } \\
\hline $15-24$ & 201 & 1 & & 1 & \\
\hline $25-34$ & 176 & $1.44(0.93-2.23)$ & 0.100 & $1.72(1.06-2.78)$ & 0.028 \\
\hline $35+$ & 49 & $0.68(0.32-1.46)$ & 0.322 & & \\
\hline \multicolumn{6}{|l|}{ Occupation } \\
\hline Unemployed & 307 & 1 & & & \\
\hline Self-employed & 104 & $1.80(1.13-2.89)$ & 0.014 & & \\
\hline Employed & 15 & $3.30(1.15-9.39)$ & 0.025 & & \\
\hline \multicolumn{6}{|l|}{ Marital status } \\
\hline Married & 382 & 1 & & 1 & \\
\hline Divorced/separated/widowed & 19 & $2.23(0.88-5.63)$ & 0.091 & $2.58(0.90-7.39)$ & 0.078 \\
\hline Never married & 25 & $1.16(0.49-2.77)$ & 0.733 & & \\
\hline \multicolumn{6}{|l|}{ Religion } \\
\hline CCAP/7th day/Baptist & 112 & 1 & & 1 & \\
\hline Other Christian & 134 & $0.52(0.30-0.91)$ & 0.021 & $0.61(0.35-1.05)$ & 0.075 \\
\hline Catholic/Anglican & 93 & $0.72(0.40-1.29)$ & 0.267 & $0.53(0.28-0.97)$ & 0.041 \\
\hline Muslim/other religions & 87 & $0.67(0.37-1.23)$ & 0.195 & & \\
\hline \multicolumn{6}{|l|}{ Tribe } \\
\hline Nyanja & 106 & 1 & & & \\
\hline Chewa & 107 & $2.23(1.19-4.15)$ & 0.011 & & \\
\hline Lomwe & 102 & $1.46(0.76-2.79)$ & 0.256 & & \\
\hline Other & 111 & $2.37(1.28-4.38)$ & 0.006 & & \\
\hline \multicolumn{6}{|l|}{ First pregnancy } \\
\hline No & 304 & 1 & & & \\
\hline Yes & 122 & $1.04(0.65-1.64)$ & 0.883 & & \\
\hline \multicolumn{6}{|l|}{ Parity } \\
\hline One child & 121 & 1 & & & \\
\hline Two children & 111 & $1.28(0.74-2.23)$ & 0.382 & & \\
\hline $3+$ children & 194 & $0.86(0.52-1.43)$ & 0.571 & & \\
\hline \multicolumn{6}{|l|}{ Timing of 1st ANC visit } \\
\hline 2nd trimester & 284 & 1 & & & \\
\hline 1st trimester & 92 & $1.48(0.91-2.41)$ & 0.116 & & \\
\hline 3rd trimester & 50 & $0.26(0.09-0.67)$ & 0.005 & & \\
\hline \multicolumn{6}{|l|}{ ANC visits } \\
\hline $4+$ & 234 & 1 & & 1 & \\
\hline Three or less & 192 & $0.31(0.19-0.49)$ & $<0.001$ & $0.29(0.18-0.48)$ & $<0.001$ \\
\hline
\end{tabular}


Table 6 Factors associated with uptake of three or more doses of IPTp-SP among postpartum women, N=426 (Continued)

\begin{tabular}{|c|c|c|c|c|c|}
\hline Characteristics & $\mathrm{N}$ & Crude Odds Ratio (95\%Cl) & Unadjusted $p$-value ${ }^{a}$ & Adjusted Odds Ratio $(95 \% \mathrm{Cl})$ & Adjusted $p$-value ${ }^{b}$ \\
\hline \multicolumn{6}{|l|}{ Gravida } \\
\hline multigravida & 194 & 1 & & & \\
\hline Secundigravida & 110 & $1.40(0.85-2.32)$ & 0.187 & & \\
\hline primigravida & 122 & $1.11(0.67-1.84)$ & 0.674 & & \\
\hline \multicolumn{6}{|c|}{ Knowledge of malaria transmission } \\
\hline knowledgeable & 386 & 1 & & & \\
\hline Inadequate Knowledge & 40 & $1.01(0.50-2.06)$ & 0.978 & & \\
\hline \multicolumn{6}{|c|}{ Knowledge of dangers of malaria in pregnancy } \\
\hline Knowledgeable & 303 & 1 & & & \\
\hline Inadequate knowledge & 123 & $0.73(0.45-1.17)$ & 0.186 & & \\
\hline \multicolumn{6}{|c|}{ Took SP under DOT each time } \\
\hline Yes & 376 & 1 & & 1 & \\
\hline No & 50 & $0.13(0.04-0.43)$ & 0.001 & $0.18(0.05-0.63)$ & 0.007 \\
\hline \multicolumn{6}{|l|}{ Permission to go to $\mathrm{HF}$} \\
\hline Small problem & 410 & 1 & & & \\
\hline Big problem & 16 & $0.78(0.25-2.46)$ & 0.669 & & \\
\hline \multicolumn{6}{|l|}{ Distance to HF } \\
\hline Small problem & 348 & 1 & & 1 & \\
\hline Big problem & 78 & $0.37(0.19-0.71$ & 0.003 & $0.49(0.23-1.06)$ & 0.070 \\
\hline \multicolumn{6}{|l|}{ Transport to HF } \\
\hline Small problem & 344 & 1 & & & \\
\hline Big problem & 82 & $0.42(0.23-0.78)$ & 0.006 & & \\
\hline \multicolumn{6}{|c|}{ Need for spouse escort to HF } \\
\hline Small problem & 276 & 1 & & 1 & \\
\hline Big problem & 150 & $2.40(1.56-3.68)$ & $<0.001$ & $2.03(1.26-3.26)$ & 0.004 \\
\hline \multicolumn{6}{|c|}{ Worried no health provider at HF } \\
\hline Small problem & 280 & 1 & & & \\
\hline Big problem & 146 & $0.49(0.30-0.78)$ & 0.003 & & \\
\hline \multicolumn{6}{|l|}{ Worried no drugs at HF } \\
\hline Small problem & 263 & 1 & & 1 & \\
\hline Big problem & 163 & $0.54(0.34-0.84)$ & 0.006 & $1.84(0.82-4.12)$ & 0.140 \\
\hline
\end{tabular}

shortage of SP in the health facility, poor fidelity in implementation of IPTp-SP by individual healthcare providers as recommended in WHO policy brief [38], and women's negative attitudes towards the use of the drug during pregnancy $[4,18,26,39]$. This implies that health care providers and community leaders have to collaborate to aggressively promote optimal ANC attendance among pregnant women and make sure that every eligible pregnant woman who attends ANC at scheduled visit receives a dose of SP. This will maximise the opportunity of optimal SP uptake in the district for those who make four or more ANC visits.
In regards to direct observation therapy (DOT), the study has revealed that pregnant women who did not take doses of SP under DOT had less likelihood of completing the recommended number of doses. GM Mubyazi, P Magnussen, C Goodman, IC Bygbjerg, AY Kitua, OE Olsen, J Byskov, KS Hansen and P Bloch [40] observed that uptake of SP was low among the study participants especially when women were allowed to take the SP at home. There are many reasons why healthcare providers allowed women to take the drug home such as shortages of clean water and cups [40], high client-to-staff ratios which reduces consultation times resulting in poor or no observation $[4,30]$. Taking 
doses of SP under direct observation therapy (DOT) of healthcare provider is one of the strategies in implementation of IPTp-SP with high fidelity [13]. This suggests that health care providers should strive to follow protocols in SP provision. Besides, health facilities' management has to strengthen their efforts in supervising ANC providers and learn about challenges they face in order find solutions of strengthening DOT, which would work in their context. Considering that resources, such as cups and clean drinking water, will never be sufficient, ZDHO and health facility management ought to be pragmatic in overcoming this challenge. One solution might be engaging community leaders to encourage pregnant women to bring with them a cup when on a scheduled ANC visit.

The odds of completing at least three doses of SP was more than 1.72 times higher among pregnant women between age group 25 to 34 than those aged between 15 to 24 years old. This result indicates that young pregnant women were under utilizing the intervention, which is similar result that Kibusi's study revealed [31]. Therefore, there is need to increase awareness of importance of completing recommended doses of IPTp-SP among pregnant women aged between 15 to 24 years as well pregnant women older than 34 years. The study has shown that poor uptake is affected by differentially on women born at different times, which might reflect women's culture of health care utilization at different ages. For instant, teen pregnancies are usually unplanned therefore are less likely to consistently utilize ANC services and subsequently miss out on receiving optimal doses of SP.

Lastly, spouse escort to health facility has shown to be positively associated with good uptake of several interventions offered at ANC [41]. However, pregnant women in the study population who had a problem with spouse escort were more likely to complete the recommended doses of SP. Mostly, these women were either divorced or windowed or on separation, hence they were socially vulnerable and probably took their situation positively by attending ANC clinics and took the recommended SP doses to avoid MiP and its adverse effects. The other possible explanation would be that they had more autonomy in relation to the use of ANC than married women [42]. This might imply that pregnant women with more autonomy are in a position to have confidence in prioritization of health care services.

This study had the following limitations. First, the study participants were recruited from health facility maternity wings and antenatal clinics. In Malawi, according to $\mathrm{Na}-$ tional Statistical Office (NSO) [Malawi] and ICF Macro [34], 20\% of births occur at home and $80 \%$ of women who received no antenatal care services deliver at home. Therefore, it would not be representative of the wider population of postpartum women in Zomba district. However, the researcher minimised the limitation by including women who delivered at home and visited the health facility within $48 \mathrm{~h}$ for check-up. Only 14\% of women age 15-49 giving birth outside health facility received a postnatal check in the first 2 days after delivery [43]. Second, the health systems factors (time and patient flow challenges, integration of services into ANC); Policy and guidance environment, human resource factors, and supply chain factors (SP availability at the facility) also play an important role in the coverage of the intervention. However, this study did not study them because the focus was primarily on pregnant women's perceptive. This limitation would under-or-overestimate the problem understudy when viewed holistically. Third, the study focused on determinants of IPTp-SP uptake in postpartum women from catchment areas of selected Health facilities in Zomba district. Hence, the results would not be generalised to all districts in Malawi because the participating district was purposively sampled because of its low uptake. However, the results could be related to other districts with similar characteristics as the sampled one. Finally, recall bias is an inherent limitation of the survey design. There was a possibility of women reporting past exposures/experiences with varying degree of accuracy. However, some of these recall biases were minimised by using records such as ANC cards and interviewing the women immediately after delivering.

\section{Conclusion}

Malaria in pregnancy continues to pose a major public health problem in sub-Saharan Africa and particularly in Malawi. However, there are a number of evidenced-based interventions for preventing MiP and one of them is IPTpSP. This study was conducted to identify the enablers and barriers of a pregnant woman completing at least three doses of IPTp-SP and estimate the uptake levels in Zomba district. The study demonstrated that there is low utilisation of SP in this population and this seems to be associated with the number of ANC visits, use of DOTs and health facility location. Therefore, community-based health promotion on optimal ANC attendance should be encouraged and antenatal care clinics should strengthen IPTp messages particularly on younger pregnant women. Zomba District Health Office in collaboration with health facilities' management have to strengthen their efforts in supervising ANC providers to enhance DOT. Further research needs to be carry out to understand factors affecting the ruralurban differential IPTp uptake to provide evidence that would address the variance.

\section{Additional file}

Additional file1: Woman questionnaire. The data collection tool that was administered to postpartum women. (DOC 325 kb) 


\section{Abbreviations}

ANC: Antenatal care; FANC: Focused antenatal care; IPTp1: Single dose of IPTp-SP; IPTp2: Two doses of IPTp-SP; IPTp3 + : Three or more doses of IPTpSP; IPTp-SP: Intermittent preventive treatment in pregnacy with Sulphadoxine Pyrimethamine; ITNs: Insecticides treated nets; MiP: Malaria in pregnancy; SP: Sulphadoxine Pyrimethamine; WHO: World Health Organization

\section{Acknowledgements}

We are grateful to the financial support for the training scheme as provided by the UNICEF/UNDP/World Bank/WHO Special programme for Research and Training in Tropical Diseases (TDR)

\section{Availability of data and materials}

The data of this study are available without restriction from the corresponding author.

\section{Authors' contributions}

SCA designed the study, performed the analysis and drafted the manuscript. GC and CM assisted with the study design. SCA, GC, CM, HC, CJ and JZ, contributed to interpretation of findings, edited and reviewed the manuscript. All authors read and approved the final manuscript.

\section{Authors' information}

SCA and HC are master's degree candidates and recipients of TDR scholarship under the Postgraduate Training Scheme in Implementation Research at the Department of Epidemiology and Biostatistics and Department of Health Policy and Management respectively, School of Public Health, University of Zambia, Lusaka, Zambia. GC, CJ and JZ are lecturers at Department of Epidemiology and Biostatistics, School of Public Health, University of Zambia, Lusaka, Zambia. CM is Dean of School of Public Health, University of Zambia, Lusaka, Zambia.

\section{Ethics approval and consent to participate}

Ethics approval was obtained from National Health Sciences Research Committee in Malawi (issued September 12, 2016, protocol number 1656) and University of Zambia Biomedical Research Ethics Committee in Zambia (issued August 3, 2016, reference number 017-06-16). Written permission to conduct the study in the health facilities was obtained from Zomba District Health Office and clinic-in-charge of each health facility. The research team informed prospective participants about the purpose of the study, procedures required of them if recruited, risks and benefits, and that they had the right to volunteer whether or not to participate in the study. Informed consent was obtained from each participants before administering the questionnaire. For women aged below 18 years, informed assent was obtained from parents or parents in-law, or their husbands if the husbands were above 18 years. The respondents were informed that they had the right to withdraw from the study at any time and without adverse consequences. The respondents were assured of privacy, confidentiality and that no names would appear on the questionnaire. Willingness to participate in the study and parental permission was confirmed by signing (finger print for illiterates) on the informed consent/assent sheet.

\section{Competing interests}

The authors declare that they have no competing interests.

\section{Publisher's Note}

Springer Nature remains neutral with regard to jurisdictional claims in published maps and institutional affiliations.

\section{Author details}

'Department of Epidemiology and Biostatistics, School of Public Health, University of Zambia, Post Box 50110, Lusaka, Zambia. ${ }^{2}$ Malawi Defence Force, Malawi Military Health Services, Kamuzu Barracks, Private Bag 43, Lilongwe, Malawi. ${ }^{3}$ Department of Health Policy and Management, School of Public Health, University of Zambia, Post Box 50110, Lusaka, Zambia.
Received: 20 November 2017 Accepted: 12 April 2018

Published online: 20 April 2018

\section{References}

1. Guyatt H, Snow R. The epidemiology and burden of plasmodium falciparum -related anemia among pregnant women in sub-Saharan Africa. Am J Trop Med Hyg. 2001;64:36-44

2. Menéndez C, D'Alessandro U, ter Kuile FO. Reducing the burden of malaria in pregnancy by preventive strategies. Lancet Infect Dis. 2007:7(2):126-35.

3. Desai M, ter Kuile F, Nosten F, McGready R, Asamoa K, Brabin B, Newman R. Epidemiology and burden of malaria in pregnancy. Lancet Infect Dis. 2007;7: 93-104.

4. Hill J, Hoyt J, van Eijk AM, D'Mello-Guyett L, Ter Kuile FO, Steketee R, Smith $\mathrm{H}$, Webster J. Factors affecting the delivery, access, and use of interventions to prevent malaria in pregnancy in sub-Saharan Africa: a systematic review and meta-analysis. PLoS Med. 2013;10(7):e1001488.

5. WHO. World Health Organization regional Office for Africa. A strategic framework for malaria prevention and control during pregnancy in the African region. Brazzaville: World Health Organization Regional Office for Africa; 2004.

6. Dellicour S, Tatem A, Guerra C, Snow R, ter Kuile F. Quantifying the number of pregnancies at risk of malaria in 2007: a demographic study. PLoS Med. 2010;7:e1000221.

7. Roll Back Malaria Partnership. The contribution of malaria control to maternal and newborn health. In: Progress \& impact. Geneva: World Health Organization; 2014.

8. Eisele TP, Larsen DA, Anglewicz PA, Keating J, Yukich J, Bennett A, Hutchinson P, Steketee RW. Malaria prevention in pregnancy, birthweight, and neonatal mortality: a meta-analysis of 32 national cross-sectional datasets in Africa. Lancet Infect Dis. 2012;12(12):942-9.

9. Guyatt $H$, Snow R. Impact of malaria during pregnancy on low birth weight in sub-Saharan Africa. Clin Microbiol Rev. 2004;17:760-9.

10. Rogerson SJ, Mwapasa V, Meshnick SR. Malaria in pregnancy: linking immunity and pathogenesis to prevention. Am J Trop Med Hyg. 2007;77(6 Suppl):14-22.

11. Steketee $R$, Nahlen B, Parise M, Menendez C. The burden of malaria in pregnancy in malaria-endemic areas. Am J Trop Med Hyg. 2001:64(1):28-35.

12. Lagerberg RE. Malaria in pregnancy: A literature review. J Midwifery Womens Health. 2008:53(3):209-15.

13. WHO: World Health Organization, WHO policy brief for the implementation of intermittent preventive treatment of malaria in pregnancy using Sulfadoxine-Pyrimethamine (IPTp-SP), April 2013 (rev. January 2014). 2013. Available from http://www.who.int/malaria/publications/atoz/Policy_brief_ IPTp-SP implementation_11april2013.pdf.pdf. Access on 5 Dec 2015.

14. Peters PJ, Thigpen MC, Parise ME, Newman RD. Safety and toxicity of Sulfadoxine/ Pyrimethamine: implications for malaria prevention in pregnancy using intermittent preventive treatment. Drug Saf. 2007;30(6): 481-501.

15. WHO: Malaria in pregnancy guidelines for measuring key monitoring and evaluation indictors. 2007. http://whqlibdoc.who.int/publications/2007/ 9789241595636_eng.pdf Accessed on 24 Nov 2015.

16. Andrews KG, Lynch M, Eckert E, Gutman J. Missed opportunities to deliver intermittent preventive treatment for malaria to pregnant women 20032013: a systematic analysis of 58 household surveys in sub-Saharan Africa. Malar J. 2015:14:1-10.

17. WHO. Updated WHO policy recommendation: intermittent preventive treatment of malaria in pregnancy using sulfadoxine-pyrimethamine (IPTpSP). Geneva: World Health Organization; [accessed on Nov 20, 2015]. Geneva: World Health Organization; 2012. Available from http://www.who. int/malaria/publications/atoz/who_iptp_sp_policy_recommendation/en/

18. Mpogoro FJ, Matovelo D, Dosani A, Ngallaba S, Mugono M, Mazigo HD. Uptake of intermittent preventive treatment with sulphadoxinepyrimethamine for malaria during pregnancy and pregnancy outcomes: a cross-sectional study in Geita district, north-western Tanzania. Malar J. 2014; 13(1):455

19. Mwendera CA, Jager C, Longwe $H$, Phiri K, Hongoro C, Mutero CM. Changing the policy for intermittent preventive treatment with sulfadoxine-pyrimethamine during pregnancy in Malawi. Malar J. 2017; 16(1):84.

20. WHO Provision of effective antenatal care, integrated management of pregnancy and childbirth (IMPAC). Standards for maternal and neonatal 
care. Geneva: World Health Organization; 2006. Available from http://www who.int/reproductivehealth/publications/maternal_perinatal_health/ effective_antenatal_care.pdf. Accessed on 26 Nov 2015

21. Roll Back Malaria Partnership. The contribution of malaria control to maternal and newborn health. Geneva: World Health Organization; 2012 Report No 10. Available from http://rbm.who.int/ProgresslmpactSeries/docs/ report17-en.pdf. Access on 22 Nov 2015

22. van Eijk AM, Hill J, Larsen DA, Webster J, Steketee RW, Eisele TP, ter Kuile FO. Coverage of intermittent preventive treatment and insecticide-treated nets for the control of malaria during pregnancy in sub-Saharan Africa: a synthesis and meta-analysis of national survey data, 2009-11. Lancet Infect Dis. 2013;13(12):1029-42.

23. d'Almeida TC, Agboton-Zoumenou MA, Garcia A, Massougbodji A, Briand V, Imorou Y, Cottrell G. Field evaluation of the intermittent preventive treatment of malaria during pregnancy (IPTp) in Benin: evolution of the coverage rate since its implementation. Parasit Vectors. 2011;4:108.

24. Exavery A, Mbaruku G, Mbuyita S, Makemba A, Kinyonge IP, Kweka H. Factors affecting uptake of optimal doses of sulphadoxine-pyrimethamine for intermittent preventive treatment of malaria in pregnancy in six districts of Tanzania. Malar J. 2014;13(1):13-22.

25. Gies S, Coulibaly SO, Ky C, Ouattara FT, Brabin BJ, D'Alessandro U. Community-based promotional campaign to improve uptake of intermittent preventive antimalarial treatment in pregnancy in Burkina Faso. Am J Trop Med Hyg. 2009;80(3):460-9.

26. Hill J, Kayentao K, Touré M, Diarwara S, Bruce J, Smedley J, Doumbo OK, Kuile FO, Webster J. Effectiveness of antenatal clinics to deliver intermittent preventive treatment and insecticide treated nets for the control of malaria in pregnancy in Mali: a household survey. PLoS One. 2014;9(3):1-13.

27. Hommerich L, von Oertzen C, Bedu-Addo G, Holmberg V, Acquah PA, Eggelte TA, Bienzle U, Mockenhaupt FP. Decline of placental malaria in southern Ghana after the implementation of intermittent preventive treatment in pregnancy. Malar J. 2007;6:144.

28. Leonard N, Eric FB, Judith AK, Samuel W. Factors associated to the use of insecticide treated nets and intermittent preventive treatment for malaria control during pregnancy in Cameroon. Arch Public Health. 2016;74:5.

29. Mubyazi GM, Bygbjerg IC, Magnussen P, Olsen O, Byskov J, Hansen KS Bloch P. Prospects, achievements, challenges and opportunities for scalingup malaria chemoprevention in pregnancy in Tanzania: the perspective of national level officers. Malar J. 2008;7:135.

30. Pell C, Straus L, Andrew EWW, Meñaca A, Pool R. Social and cultural factors affecting uptake of interventions for malaria in pregnancy in Africa: a systematic review of the qualitative research. PLoS One. 2011;6(7):e22452.

31. Kibusi SM, Kimunai E, Hines CS. Predictors for uptake of intermittent preventive treatment of malaria in pregnancy (IPTp) in Tanzania. BMC Public Health. 2015;15(1):540.

32. Mwandama D, Gutman J, Wolkon A, Luka M, Jafali J, Ali D, Mathanga DP, Skarbinski J. The use of intermittent preventive treatment in pregnancy and insecticide-treated bed nets for malaria prevention by women of childbearing age in eight districts in Malawi. Malar J. 2015;14(1):1-10.

33. Launiala A, Honkasalo M-L. Ethnographic study of factors influencing compliance to intermittent preventive treatment of malaria during pregnancy among Yao women in rural Malawi. Trans R Soc Trop Med Hyg. 2007:101(10):980-9.

34. National Statistical Office (NSO) [Malawi] and ICF Macro. Malawi demographic and health survey 2010. Zomba and Calverton: NSO and ICF Macro; 2011.

35. WHO. Evidence review group: intermittent preventive treatment of malaria in pregnancy (IPTp) with sulfadoxine-pyrimethamine (SP). Geneva: World Health Organization; 2012. Available from http://www.who.int/malaria/ mpac/sep2012/iptp_sp_erg_meeting_report_july2012.pdf

36. Onoka CA, Hanson K, Onwujekwe OE. Low coverage of intermittent preventive treatment for malaria in pregnancy in Nigeria: demand-side influences. Malar J. 2012;11:82.

37. National Malaria Control Programme (NMCP) [Malawi] and ICF International. Malaria Indicator survey (MIS) 2014. Lilongwe and Rockville: NMCP and ICF International; 2015

38. WHO. World Health Organization, WHO policy brief for the implementation of intermittent preventive treatment of malaria in pregnancy using Sulfadoxine-Pyrimethamine (IPTp-SP), 2013: World Health Organization; 2013. http://www.who.int/malaria/publications/atoz/Policy_brief_IPTp-SP_ implementation_11april2013.pdf.pdf. Accessed 22 Nov 2015.
39. Bausell $L$, Wolf K. Treatment uptake and availability of antimalarialdrugs for intermittent preventative treatment in pregnant women in Malawi. Arlington, Va: USAID DELIVER PROJECT; 2015. Task Order 7

40. Mubyazi GM, Magnussen P, Goodman C, Bygbjerg IC, Kitua AY, Olsen OE, Byskov J, Hansen KS, Bloch P. Implementing intermittent preventive treatment for malaria in pregnancy: review of prospects, achievements, challenges and agenda for research. Open Trop Med J. 2008;1:92-100.

41. Tweheyo R, Konde-Lule J, Tumwesigye NM, Sekandi JN. Male partner attendance of skilled antenatal care in peri-urban Gulu district, northern Uganda. BMC Pregnancy Childbirth. 2010;10(1):53.

42. Simkhada B, Teijlingen ER, Porter M, Simkhada P. Factors affecting the utilization of antenatal care in developing countries: systematic review of the literature. J Adv Nurs. 2008;61(3):244-60.

43. National Statistical Office (NSO) [Malawi] and ICF. Malawi demographic and health survey 2015-16. Zomba and Rockville: NSO and ICF; 2017.

\section{Ready to submit your research? Choose BMC and benefit from:}

- fast, convenient online submission

- thorough peer review by experienced researchers in your field

- rapid publication on acceptance

- support for research data, including large and complex data types

- gold Open Access which fosters wider collaboration and increased citations

- maximum visibility for your research: over $100 \mathrm{M}$ website views per year

At BMC, research is always in progress.

Learn more biomedcentral.com/submissions 